\title{
Human capital and productivity
}

\author{
Angel de la Fuente* \\ Instituto de Análisis Económico (CSIC)
}

January 2011

\begin{abstract}
This paper surveys the empirical literature on human capital and productivity and summarizes the results of my own work on the subject. On balance, the available evidence suggests that investment in education has a positive, significant and sizable effect on productivity growth. According to my estimates, moreover, the social returns to investment in human capital are higher than those on physical capital in most EU countries and in many regions of Spain.
\end{abstract}

Keywords: human capital, productivity, growth, measurement error

JEL Classification: O40, I20, O30, C19

\footnotetext{
* This paper has been prepared for a special issue of Nordic Economic Policy Review on productivity and competitiveness. It draws heavily on joint work with R. Doménech and other coathors that has been partially financed by the European Commission, the OECD, the research department of BBVA and the Spanish Ministry of Science and Innovation (through grant no. ECO2008-04837/ECON and its predecessors).
} 


\section{Introduction}

One of the most distinctive features of the "new" theories of economic growth has been the broadening of the relevant concept of capital. While traditional neoclassical models focused almost exclusively on the accumulation of physical capital (equipment and structures), more recent contributions have attributed increasing importance to the accumulation of human capital and productive knowledge and to the interaction between these two factors. The empirical evidence, however, has not always been consistent with the new theoretical models. In the case of human capital, in particular, a number of studies have produced discouraging results. Educational variables are often not significant or even enter with the "wrong" sign in growth regressions, particularly when these are estimated using differenced specifications or panel techniques. The accumulation of negative results in the literature during the second half of the nineties generated a growing skepticism about the role of schooling in the growth process and even led some authors (see in particular Pritchett, 2001) to seriously consider the reasons why educational investment may fail to contribute to productivity growth.

Many researchers in the area, however, held on to more optimistic views. They (we) argue that the negative results found in certain studies can be explained by technical problems that have a lot to do with the difficulty of measuring human capital correctly. This article provides a quick review of several strands of a literature that provides evidence in support of this hypothesis and a more detailed summary of my own work on the subject. The paper is organized as follows. Section 2 sketches the theoretical framework that has guided most studies of the contribution of education to economic growth, reviews the main empirical specifications used in the literature and briefly discusses some of its key results. Section 3 highlights some of the shortcomings of the cross-country schooling data sets most commonly used in the early empirical literature, discusses their implications for attempts to estimate the contribution of education to productivity growth and introduces a convenient indicator of data quality that can be used to quantify the information content of alternative schooling series and to estimate the size of the bias caused by measurement error. Section 4 summarizes the main findings of a series of papers I have written mostly in collaboration with Rafael Doménech. In them, we construct new attainment series for 21 OECD countries and for the regions of Spain, develop measures of the information content of these and other schooling series and estimate a variety of growth specifications for both samples. Using these results we have also constructed a set of metaestimates of the coefficient of human capital in an aggregate Cobb-Douglas production function that correct for the downward bias generated by measurement error. With this correction, we find that the contribution of investment in human capital to productivity growth is positive, quite sizable and implies rather respectable social returns that, for most territories in our two samples, compare quite favorably with those on physical capital. 


\section{Human capital and economic growth: an overview of the literature}

Theoretical models of human capital and growth are built around the hypothesis that the knowledge and skills embodied in humans directly raise productivity and increase an economy's ability to develop and to adopt new technologies. In order to explore its implications and open the way for its empirical testing, this basic hypothesis is generally formalized in one of two (not mutually exclusive) ways. The simplest one involves introducing the stock of human capital (which will be denoted by $H$ throughout this paper) as an additional input in an otherwise standard aggregate production function linking national or regional output to the stocks of productive inputs (generally employment and physical capital) and to an index of technical efficiency or total factor productivity (TFP). The second possibility is to include $H$ in the model as a determinant of the rate of technological progress (that is, the rate of growth of TFP). This involves specifying a technical progress function that may include as additional arguments some indicator of investment in R\&D and a measure of the "technological gap", that is, of the distance between each country's productive technology and the best practice frontier. In what follows, I will refer to the first of these links between human capital and productivity as level effects (because the stock of human capital has a direct impact on the level of output) and to the second one as rate effects (because $H$ affects the growth rate of output through TFP). Box 1 develops a simple model of growth with human capital that formalizes the preceding discussion and incorporates both effects.

\section{Box 1: A descriptive model of human capital and growth}

This box develops a simple model of growth and human capital that has two components: an aggregate production function and a technical progress function. The production function will be assumed to be of the Cobb-Douglas type:

$$
\text { (B.1) } Y_{i t}=A_{i t} K_{i t}{ }^{\alpha_{k}} H_{i t}{ }^{\alpha_{h}} L_{i t}{ }^{\alpha l}
$$

where $Y_{i t}$ denotes the aggregate output of country $i$ at time $t, L_{i t}$ is the level of employment, $K_{i t}$ the stock of physical capital, $H_{i t}$ the average stock of human capital per worker, generally measured by school attainment, and $A_{i t}$ an index of technical efficiency or total factor productivity (TFP) which summarizes the current state of the technology and, possibly, omitted factors such as geographical location, climate, institutions and endowments of natural resources. The coefficients $\alpha_{i}$ (with $i=k, h, l$ ) measure the elasticity of output with respect to the stocks of the different factors. An increase of $1 \%$ in the stock of human capital per worker, for instance, would increase output by $\alpha_{h} \%$, holding constant the stocks of the other factors and the level of technical efficiency.

Under the standard assumption that (B.1) displays constant returns to scale in physical capital and labor while holding average attainment constant, (i.e. that $\alpha_{k}+\alpha_{l}=1$ ), we can define a per capita production function that will relate average labor productivity to average schooling and to the stock of capital per worker. Letting $Q=Y / L$ denote output per worker and $Z=K / L$ the stock of capital per worker and dividing both sides of (B.1) by total employment, $L$, we have:

(B.2) $Q=A Z^{\alpha_{k}} H^{\alpha_{h}}$ 


\section{Box 1 -- continued}

The technical progress function describes the determinants of the growth rate of total factor productivity. I will assume that country i's TFP level can be written in the form:

$$
\text { (B.3) } A_{i t}=B_{t} X_{i t}
$$

where $B_{t}$ denotes the world "technological frontier" (i.e. the maximum attainable level of efficiency in production given the current state of scientific and technological knowledge) and $X_{i t}=A_{i t} / B_{t}$ is (an inverse indicator of) the "technological gap" between country $i$ and the world frontier. It will be assumed that $B_{t}$ grows at a constant and exogenous rate, $g$, and that the growth rate of $X_{i t}$ is given by

$$
\text { (B.4) } \Delta x_{i t}=\gamma_{i o}-\lambda x_{i t}+\gamma H_{i t}
$$

where $x_{i t}$ is the $\log$ of $X_{i t}$ and $\gamma_{i o}$ a country fixed effect that helps control for omitted variables such as R\&D investment. Notice that this specification incorporates a technological diffusion or catch-up effect. If $\lambda>0$, countries that are closer to the technological frontier will experience lower rates of TFP growth. As a result, relative TFP levels will tend to stabilize over time and their steady-state values will be partly determined by the level of schooling.

Some recent theoretical models suggest that the accumulation of human capital may give rise to important externalities that would justify corrective public interventions. The problem arises because some of the benefits of a more educated labor force will typically "leak out" and generate output gains that cannot be appropriated in the form of higher earnings by those who undertake the relevant investment, thereby driving a wedge between the private and social returns to education. Lucas (1988), for example, suggests that the average stock of human capital at the economy-wide level increases productivity at the firm level holding the firm's own stock of human capital constant. It is also commonly assumed that the rate effects of human capital on technical progress include a large externality component because it is difficult to appropriate privately the full economic value of new ideas. Azariadis and Drazen (1990), and implicitly Lucas (1988) as well, stress that younger cohorts are likely to benefit from the knowledge and skills accumulated by their elders, thus generating potentially important intergenerational externalities that operate both at home and in school. The literature also suggests that human capital can generate more diffuse "civic" externalities, as an increase in the educational level of the population may help reduce crime rates or contribute to the development of more effective institutions.

\section{From theory to data: alternative approaches to empirical analysis}

Empirical studies of the effects of human capital on productivity (or more broadly, of the determinants of economic growth) have followed one of two alternative approaches. The first one involves the specification and estimation of an ad-hoc equation relating growth in total or per capita output to a set of variables that are thought to be relevant on the basis of informal theoretical considerations. The second approach is based on the estimation of a structural relation between the level of output or its growth rate and the relevant explanatory variables 
that is derived from an explicit theoretical model built around an aggregate production function and, possibly, a technical progress function of the type described in Box 1.

This basic framework for the "structural" analysis of the determinants of growth can give rise to a large number of empirical specifications. Some of the most common examples are discussed in Box 2 . The production function can be estimated directly with the relevant variables expressed

Box 2: Some common empirical specifications

For estimation purposes it is generally convenient to work with the production function written in logarithms or in growth rates. Using lower case letters to denote logarithms, and the combination of lower case letters and the symbol " $\Delta$ " to denote growth rates, the production function given by equation (B.1) in Box 1 yields the following two specifications:

$$
\begin{aligned}
& \text { (B.5) } y_{i t}=a_{i t}+\alpha_{k} k_{i t}+\alpha_{h} h_{i t}+\alpha_{l} l_{i t}+\varepsilon_{i t} \\
& \text { (B.6) } \Delta y_{i t}=\Delta a_{i t}+\alpha_{k} \Delta k_{i t}+\alpha_{h} \Delta h_{i t}+\alpha_{l} \Delta l_{i t}+\Delta \varepsilon_{i t}
\end{aligned}
$$

where $\varepsilon_{i t}$ and $\Delta \varepsilon_{i t}$ are stochastic disturbances.

One difficulty that arises at this point is that both of these equations contain terms that are not directly observable (in particular the level of TFP, $a_{i t}$, or its growth rate, $\Delta a_{i t}$ ). To proceed with the estimation, it is necessary to make further assumptions about the behavior of these terms. Different assumptions will generate different econometric specifications. The simplest possibility is to assume that the rate of technical progress is constant over time and across countries, i.e. that $\Delta a_{i t}=g$ for all $i$ and $t$. In this case, $g$ can be estimated as the regression constant in equation (B.6) and $a_{i t}$ is replaced in equation (B.5) by $a_{i o}+g t$, where $a_{i o}$ and $g$ give rise to country-specific constants and a common trend respectively. An alternative and more sophisticated approach is to specify $\Delta a_{i t}$ in equation (B.6) as a function of other variables. One possible specification is the one given by the technical progress function described by equations (B.3) and (B.4) in Box 1.

When data on factor stocks or their growth rates are not available (or are not considered reliable), a generalized Solow model can be used to approximate these variables in terms of observed investment rates. In such a model, long-term equilibrium values of factor ratios are simple functions of investment rates, and the behavior of these ratios away from such an equilibrium can be approximated as a function of investment rates and initial income per worker. If we are willing to assume that most countries are reasonably close to their long-run equilibria, equation (B.5) can be replaced by an equation relating output per worker to investment rates in physical and human capital. Otherwise, the relevant equation will involve the growth rate of output and it will include initial output per worker as an additional regressor in order to pick up transitional dynamics along the adjustment to the long-run equilibrium. Two rather standard specifications of the resulting steady state and convergence equations (which do not allow for rate effects) would be

$$
\text { (B.7) } q_{i t}=a_{i 0}+g t+\frac{\alpha_{k}}{1-\alpha_{k}-\alpha_{h}} \ln \frac{s_{k i t}}{\delta+g+n_{i t}}+\frac{\alpha_{h}}{1-\alpha_{k}-\alpha_{h}} \ln \frac{s_{h i t}}{\delta+g+n_{i t}}
$$

and

$$
\text { (B.8) } \Delta q_{i t}=g+\beta\left(a_{i o}+g t\right)+\beta\left(\frac{\alpha_{k}}{1-\alpha_{k}-\alpha_{h}} \ln \frac{s_{k i t}}{\delta+g+n_{i t}}+\frac{\alpha_{h}}{1-\alpha_{k}-\alpha_{h}} \ln \frac{s_{h i t}}{\delta+g+n_{i t}}\right)-\beta q_{i t}
$$

where $q$ is the log of output per worker, $s_{k}$ and $s_{h}$ stand for investment in physical and human capital measured as a fraction of GDP, $n$ for the rate of growth of employment or the labor force and $\delta$ for the rate of depreciation (which is assumed to be the same for both types of capital). The parameter $\beta$ measures the speed of convergence towards the long-run equilibrium or steady state and can be shown to be a function of the degree of returns to scale in both types of capital considered jointly and of the length of the period over which we are taking observations. 
in levels or in growth rates when reliable data are available for the stocks of all the relevant production inputs. Alternatively, its parameters can be recovered from other specifications (convergence and steady state equations) that are designed for estimation when only data on investment flows (rather than factor stocks) are available. These specifications can be derived from a production function by replacing factor stocks or their growth rates by convenient approximations in terms of investment rates using the procedure developed by Mankiw, Romer and Weil (1992) within the framework of a generalized Solow model with several types of capital.

\section{Empirical evidence: a bird's eye view}

A large number of empirical studies have analyzed the relationship between human capital and economic growth using the different specifications I have outlined above. ${ }^{1}$ Early attempts in this direction, by and large, produced positive results that tended to confirm economists' traditionally optimistic views regarding the macroeconomic payoff to investment in education. Landau (1983), Baumol et al (1989), Barro (1991) and Mankiw, Romer and Weil (1992), among many others, find that a variety of educational indicators have the expected positive effect on output growth. During the second half of the nineties, however, a new round of empirical papers produced rather disappointing results on the effects of schooling on aggregate productivity. Unlike most previous studies, most of these papers used pooled quinquennial data and relied on either panel techniques or the use of differenced specifications to control for unobserved country heterogeneity. In this setting, educational variables are often found to be insignificant or even enter with the "wrong" sign in growth regressions. (See for instance Benhabib and Spiegel (1994), Islam (1995), Caselli, Esquivel and Lefort (1996) and Pritchett (2001)).

While some researchers have been willing to take such counterintuitive results at face value, many others have been rather skeptical (see for instance Barro (1997)). These authors have tended to attribute negative results on schooling and growth to various econometric and specification problems and to poor data quality. Measurement error, in particular, has been widely recognized to be a potentially important problem for two reasons. First, because the series of average years of schooling commonly used in the literature are likely to contain a lot of noise and, second, because years of schooling can be expected to be a very imperfect measure of skills in any event. The first problem, in addition, is likely to be particularly important in a panel setting, where parameter estimates rely heavily on the time-series variation of the data, because measurement error arising from changes in classification and data collection criteria tends to generate a lot of spurious volatility in the schooling series that will make it difficult to identify its contribution to productivity growth.

Although it is too early for the issue to have been conclusively settled, my reading of the evidence accumulated over the last decade or so is optimistic. We have good reasons to believe 
that the negative results found in some of the previous literature can indeed be largely attributed to deficiencies in the human capital data used in earlier studies. Papers that make use of improved data sets on attainment or allow for measurement error strongly suggest that increases in average schooling do indeed have a substantial impact on productivity growth. Results are generally even stronger and sharper when direct measures of skill levels are used to proxy for human capital, suggesting that improvements in the quality of schooling can have an even larger effect on aggregate output than increases in its quantity.

The wave of negative results on the growth effects of education that arrived in the second half of the nineties is clearly associated with the introduction of panel data techniques. While early studies relied on cross-section data (working with a single observation per country that described average behavior over a period of several decades), studies in the second group have used several observations per country, taken over shorter periods, and have employed panel techniques or differenced specifications that basically eliminate the cross-section variation in the data before proceeding to the estimation. While theses estimation techniques have the important advantage that they control for unobservable differences across countries, they also have some disadvantages. Perhaps the main one is that they are more sensitive to measurement error in the data as errors tend to be greater in the time-series than in the cross-section dimension because they tend to cancel out when we work with averages over long periods. This suggests, as I have already noted, that a possible explanation of the negative results obtained in panel data studies has to do with the poor quality of the schooling data that have been used until recently in the growth literature. As we will see below, most of the earlier databases on international schooling levels contain large amounts of noise that can be traced back to various inconsistencies of the primary data used to construct them. The existence of this noise induces a downward bias in the estimation of the coefficients that measure the impact of human capital (that is, a tendency to underestimate their values) because it generates spurious variability in the stock of human capital that is not matched by proportional changes in the level of productivity.

A number of recent studies provide evidence that is consistent with this hypothesis. Starting with Krueger and Lindhal (K\&L 2001), some authors have constructed statistical indicators of the informational content of different attainment series (reliability ratios) that can be used to calculate the likely size of the attenuation bias and conclude that the value of this ratio is sufficiently low to explain the lack of significance of educational indicators in previous studies. Other authors, including Cohen and Soto (2007), de la Fuente and Doménech (D\&D, 2001a and $\mathrm{b}$ and 2006) and Barro and Lee (2010), have tried to improve the signal-to-noise ratio in the schooling series by exploiting new sources of information and introducing different corrections. They find that the results concerning the impact of education on growth improve considerably when these revised series are used. I will return to these issues in much greater detail in the following two sections.

\footnotetext{
${ }^{1}$ For a more detailed survey of the relevant literature, see section 3 of the Appendix to de la Fuente and Ciccone (2003).
} 
Another interesting development is the use of cross-country data on direct measures of skill which may provide better proxies for the stock of human capital than years of schooling. While such data are still rather scarce, some recent papers suggest that this is likely to be a very fruitful line of research. Hanushek and several coauthors ${ }^{2}$ construct indicators of labor force quality using mean country scores in a number of international student achievement tests in mathematics, science and reading, while Coulombe et al (2004) use data drawn from IALS, an international study on the skill level of the adult population conducted by the OECD and Statistics Canada. In both cases, the results of growth regressions point to even larger output effects than those obtained using even revised attainment data. While not entirely free of problems, these estimates do suggest that the quality of education is likely to be at least as important as its quantity and that the return to improvements in schooling quality could be extraordinarily high, for not only are their expected benefits large, but the relevant costs will generally be much lower than those of increasing attainment for they do not involve a further sacrifice of student time and output.

\section{Cross-country data on schooling: problems and consequences}

Most governments gather information on a number of educational indicators through population censuses, labor force surveys and specialized studies and surveys. Various international organizations collect these data and compile comparative statistics that provide easily accessible and (supposedly) homogeneous information for a large number of countries. The most comprehensive regular source of international educational statistics is UNESCO's Statistical Yearbook. This publication provides reasonably complete yearly time series on school enrollment rates by level of education for most countries in the world and contains some data on the educational attainment of the adult population, government expenditures on education, teacher/pupil ratios and other variables of interest. ${ }^{3}$

The UNESCO enrollment series have been used in a large number of empirical studies of the link between education and productivity. In many cases this choice reflects the easy availability and broad coverage of these data rather than their theoretical suitability for the purpose of the study. Enrollment rates can probably be considered an acceptable, although imperfect, proxy for the flow of educational investment but they are not necessarily a good indicator of the existing stock of human capital since average educational attainment (which is often the more interesting variable from a theoretical point of view) responds to investment flows only gradually and with a very considerable lag.

In an attempt to remedy these shortcomings, a number of researchers have constructed data sets that attempt to measure directly the educational stock embodied in the population or labor force of large samples of countries during a period of several decades. These data sets have generally been constructed by combining the available data on attainment levels with the

\footnotetext{
2 See among others Hanushek and Kimko (2000) and Hanushek and Wossman (2008 and 2009).

3 Other useful sources include the UN's Demographic Yearbook, which also reports educational attainment levels by age group and, in recent years, the OECD's annual report on education in its member countries (Education at a Glance), which contains a great deal of information about the inputs and outputs of the educational system.
} 
UNESCO enrollment figures to obtain series of average years of schooling and of the composition of the population or labor force by educational level. The best known early attempts in this line are the work of Kyriacou (1991), the first versions of the Barro and Lee data set (1993, 1996 and 2000) and the series constructed by World Bank researchers (Lau, Jamison and Louat (1991), Lau, Bhalla and Louat (1991) and Nehru, Swanson and Dubey (NSD, 1995).

In de la Fuente and Doménech (D\&D, 2006) we briefly review the methodology used in these studies and compare the different data sets with each other, focusing in particular on the OECD, where the quality of the available information should in principle be better than in developing countries. The analysis of the different series reveals very significant discrepancies among them in terms of the relative positions of many countries and implausible estimates or time profiles for at least some of them. Although the various studies generally coincide when comparisons are made across broad regions (e.g. the OECD vs. LDCs in various geographical areas), the discrepancies are very important when we focus on the group of industrialized economies. Another cause for concern is that existing estimates often display extremely large changes in attainment levels over periods as short as five years (particularly at the secondary and tertiary levels).

To a large extent, these problems have their origin in the deficiencies of the underlying primary data. As Behraman and Rosenzweig (1994) have noted, there are good reasons to worry about the accuracy and consistency of UNESCO's data on both attainment levels and enrollment rates. Our analysis of the different schooling data sets confirms this diagnostic and suggests that many of the problems detected in these data can be traced back to shortcomings of the primary statistics, which do not seem to be consistent, across countries or over time, in their treatment of vocational and technical training and other courses of study, and reflect at times the number of people who have started a certain level of education and, at others, those who have completed it.

\section{Attenuation bias and a measure of data quality}

The poor quality of cross-country schooling data is a serious concern because it tends to obscure the relationship between the variables of interest and generates a tendency to underestimate the impact of human capital on productivity. To understand the origin of the attenuation bias caused by measurement error, assume that the level of productivity, $Q$, is a linear function of the stock of human capital, $H$, given by

$$
\text { (1) } Q=b H+u
$$

where $u$ is a random disturbance. Given this relationship, variations in the stock of human capital, $H$, will induce changes in $Q$, and the relative magnitude of the variations in these two variables will allow us to estimate the value of the coefficient $b$. Now, if $H$ is measured with error, that is, if what we observe is not $H$ itself but a noisy proxy for it, say

(2) $P=H+\varepsilon$, 
where $\varepsilon$ is a random measurement error term, then part of the apparent variation in the stock of human capital (over time and across countries) will be due to measurement error --that is, it will be noise rather than true signal. Since such variations logically do not induce any response in $Q$, this variable will appear to be less sensitive to $H$ than it really is, thereby biasing toward zero the estimated value of $b$.

In summary, attenuation bias arises because measurement error introduces "noise" that tends to hide the true relationship between the variables of interest. It can be shown that the size of the bias will be inversely related to the information content of the series, as measured by its reliability ratio, $r$. This indicator is defined as the ratio between the signal and the sum of signal and noise contained in the data, that is,

$$
\text { (3) } r \equiv \frac{\operatorname{var} H}{\operatorname{var} P}=\frac{\operatorname{var} H}{\operatorname{var} H+\operatorname{var} \varepsilon}
$$

where var $H$ measures the signal contained in the series (i.e. the true variation in human capital) and var $\varepsilon$ the noise that distorts it. ${ }^{4}$ This ratio is very useful, first because it provides an indicator of the information content of each series, and second because the error in the estimation will be inversely proportional to its value. As a result, the reliability ratio can be used to correct the attenuation bias so as to obtain consistent estimators of the parameter of interest (i.e. estimators that are not biased in large samples).

Since $H$ and $\varepsilon$ are not observed separately, reliability ratios cannot be computed directly. They can, however, be estimated using a procedure developed by Krueger and Lindhal (2001) whenever several noisy proxies are available for the variable of interest. Box 3 describes this procedure and an extension of it developed by de la Fuente and Doménech (2006).

\section{Box 3: Estimating reliability ratios}

Let $P_{1}=H+\varepsilon_{1}$ and $P_{2}=H+\varepsilon_{2}$ be two alternative proxies for the stock of human capital, $H$. It is easy to check that if the error terms of the two series, $\varepsilon_{1}$ and $\varepsilon_{2}$, are not correlated with each other, then the covariance between $P_{1}$ and $P_{2}$ can be used to estimate the variance of $H$, which is the only unknown magnitude in equation (3). It follows that, under this assumption, $r_{1}$ can be estimated as

$$
\text { (B.9) } \hat{r}_{1}=\frac{\operatorname{cov}\left(P_{1}, P_{2}\right)}{\operatorname{var} P_{1}}
$$

which turns out to be the formula for the OLS estimator of the slope coefficient of a regression of $P_{2}$ on $P_{1}$. Hence, to estimate the reliability of $P_{1}$ we run a regression of the form $P_{2}=c+r_{1} P_{1}$. ${ }^{5}$ Notice, however, that if the measurement errors of the two series are positively correlated $\left(E \varepsilon_{1} \varepsilon_{2}>0\right)$ as may be expected in many cases, $\hat{r}_{1}$ will overestimate the reliability ratio and hence understate the extent of the attenuation bias induced by measurement error.

\footnotetext{
4 Notice that the denominator of the last expression given in (3) implicitly assumes that the measurement error term, $\varepsilon$, is not correlated with $H$.

5 Intuitively, regressing $P_{2}$ on $P_{1}$ gives us an idea of how well $P_{1}$ explains the true variable $H$ because measurement error in the dependent variable $\left(P_{2}\right.$ in this case) will be absorved by the disturbance without generating any biases. Hence, it is almost as if we were regressing the true variable on $P_{1}$.
} 


\section{Box 3 -- continued}

In de la Fuente and Doménech (2006) we develop an extension of this procedure that can be used to construct a minimum-variance estimator of the reliability ratio whenever more than two noisy proxies are available for the same underlying variable, under the maintained assumption that measurement errors are uncorrelated across data sets. As in K\&L, the reliability ratio $r_{k}$ of a given series of average years of schooling ( say $S_{k}$ ) is estimated by using $S_{k}$ to try to explain alternative estimates of the same variable $\left(S_{j}\right.$ with $\left.j \neq k\right)$. The main difference is that, rather than running a set of independent pairwise regressions with different data sets, the efficient estimator of the reliability ratio for data set $j$ can be obtained as the slope coefficient of a restricted SUR model of the form

$$
\text { (B.10) } P_{k}=c_{k}+r_{j} P_{j}+u_{k} \text { for } k=1 \ldots, K
$$

where we constrain $r_{j}$ to be the same for all "reference" data sets, $k$, and $k$ varies over the last available version of all data sets different from $j$. The reliability ratio of Barro and Lee's (2000) data set, for instance, is estimated by using these authors' estimate of average years of schooling as the explanatory variable in a set of regressions where the reference (dependent) variables are the average years of schooling estimated by Kyriacou (1991), NSD (1995), Cohen and Soto (2001) and de la Fuente and Doménech (2006). Other versions of the Barro and Lee data set, however, are not used as a reference because the correlation of measurement errors across the same family of schooling series is almost certainly very high and this will artificially inflate the estimated reliability ratio.

\section{Some results for the OECD and for the regions of Spain}

The preceding discussion suggests two complementary ways to deal with the problems caused by poor schooling data. One is to try to improve the quality of the data by drawing on new primary sources and introducing various corrections to neutralize the effects of changes in classification criteria, and the other is to use estimates of reliability ratios to correct for attenuation bias. In a series of related papers Rafael Doménech and myself (D\&D 2000, 2001a and b, 2002, 2006 and 2008) have followed both of these strategies using data for 21 OECD countries and for the regions of Spain. In both cases, the first step has been to construct new schooling series which attempt to increase the signal to noise ratio. In the case of Spain (D\&D, 2008), the task has been relatively simple since the required primary information is readily available in the decennial censuses and in municipal registers, both of which have been compiled using clear and relatively stable classification criteria.

\subsection{A new data set}

The OECD series (D\&D 2000, 2001b and 2006) required considerably more work. We first collected all the information we could find on the distribution of the adult population by educational level in OECD countries. We used both international publications and national sources (census reports and surveys, statistical yearbooks and unpublished data supplied by national governments and by the OECD in response to a request for information that was accompanied by a preliminary version of our data set). Next, we tried to reconstruct a plausible time profile of attainment in each country using all the available data and a bit of common sense. For those countries for which reasonably complete series were available, we relied primarily on national sources. For the rest, we started from the most plausible set of attainment estimates available around 1990 or 1995 (taken generally from OECD sources) and proceeded 
backwards, trying to avoid unreasonable jumps in the series that could only reflect changes in classification criteria. In some cases, the construction of the series involved subjective judgments to choose among alternative census or survey estimates when several were available. At times, we have also reinterpreted some of the data from international compilations as referring to somewhat broader or narrower schooling categories than the reported one. ${ }^{6}$ Missing data points lying between available census observations were filled in by simple linear interpolation. Missing observations prior to the first census observation were estimated, whenever possible, by backward extrapolations that made use of census information on attainment levels disaggregated by age group. ${ }^{7}$

\subsection{How good are different schooling series?}

In de la Fuente and Doménech (D\&D, 2002 and 2006) we use the procedure described in Box 3 to estimate the reliability ratios of the series of years of schooling most commonly used in the growth literature, restricting ourselves to the sample of 21 OECD countries covered by the data set described in the previous section. This indicator is constructed for several transformations of the series of average years of schooling after removing period means from all the series so as to eliminate fixed time effects. In particular, we estimate reliability ratios for years of schooling measured in levels $\left(S_{i t}\right)$ and in logs $\left(s_{i t}\right)$, for average annual changes in both levels and logs measured across successive quinquennial observations $\left(\Delta S_{i t}\right.$ and $\left.\Delta s_{i t}\right)$, and for log years of schooling measured in deviations from their country means $\left(s_{i t}-s_{i}\right)$. Notice that $\Delta s_{i t}$ corresponds to annual growth rates and $s_{i t}-s_{i}$ is the "within" transformation often used to remove fixed effects.

The results are shown in Table 1 with the different data sets arranged by decreasing average reliability ratios. The last row of the table shows the average value of the reliability ratio for each type of data transformation (taken across data sets), and the last column displays the average reliability ratio of each data set (taken across transformations). Our mean estimate of the reliability ratio for all the series and transformations is 0.335 . Since this variable must lie between zero and one (with zero indicating that the series contains only noise and one that it is measured without error $)^{8}$ this result suggests that the average estimate of the coefficient of schooling in a growth equation is likely to suffer from a substantial downward bias, even

\footnotetext{
6 Clearly, the construction of our series involves a fair amount of guesswork. Our "methodology" looks decidedly less scientific than the apparently more systematic estimation procedures used by other authors starting from supposedly homogeneous data. However, even a cursory examination of the data shows that there is no such homogeneity. Hence, we have found it preferable to rely on judgment to try to piece together the available information in a coherent manner than to take for granted the accuracy of the primary data. The results do look more plausible than most existing series, at least in terms of their time profile and, as I will show below, perform rather well in terms of a statistical indicator of data quality.

7 A closely related paper, both in terms of its objectives and its methodology, is Cohen and Soto (2007). These authors construct a schooling data set for a much larger sample of countries using census and survey data from UNESCO, the OECD's in-house educational data base, and the websites of national statistical agencies, together with enrollment rates from UNESCO and other sources.

8 This is true as long as the measurement error terms of the different series are uncorrelated with each other and with $H$. As can be seen in Table 1, some of our estimates of the reliability ratio lie outside this interval, which implies some violation of this assumption. In D\&D (2002) we construct alternative
} 
without taking into account the further loss of signal that arises when additional regressors are included in these equations (see D\&D 2006). The bias will be smaller when the data are used in levels or logs, but is likely to be very large in fixed effects or differenced specifications. The average reliability ratio is only 0.254 for the data in quinquennial log differences, and 0.090 for level differences taken at the same frequency.

Table 1: SUR estimates of reliability ratios, OECD sample

\begin{tabular}{lccccccc}
\hline & $S_{i t}$ & $s_{i t}$ & $\Delta S_{i t}$ & $\Delta s_{i t}$ & $s_{i t}{ }^{-} s_{i}$ & $\Delta s_{i t}-\Delta s_{i}$ & Average \\
DED (2002) & 0.754 & 0.775 & 0.337 & 0.769 & 0.917 & 0.246 & 0.633 \\
CES (2001) & 0.806 & 0.912 & 0.330 & 0.467 & 0.547 & 0.185 & 0.541 \\
DED (2000) & 0.720 & 0.761 & 0.100 & 0.550 & 0.818 & 0.074 & 0.504 \\
Kyr. (1991) & 0.723 & 0.600 & 0.024 & 0.065 & 0.111 & 0.026 & 0.258 \\
BEL (2000) & 0.707 & 0.603 & -0.018 & 0.045 & 0.178 & -0.016 & 0.250 \\
BEL (1996) & 0.559 & 0.516 & -0.017 & 0.039 & 0.146 & -0.007 & 0.206 \\
BEL (1993) & 0.526 & 0.436 & -0.019 & 0.029 & 0.121 & -0.017 & 0.179 \\
NSD (1995) & 0.278 & 0.330 & -0.021 & 0.066 & 0.095 & -0.115 & 0.106 \\
Average & 0.634 & 0.617 & 0.090 & 0.254 & 0.367 & 0.047 & 0.335 \\
& & & & & & &
\end{tabular}

\section{Notes:}

- All series are measured in deviations from their respective sample means in each period prior to estimation.

- Key: $D \mathcal{E} D=$ de la Fuente and Doménech (preliminary and final versions); $C \mathcal{E S}=$ Cohen and Soto (data taken from the working paper version published in 2001); Kyr = Kyriacou; BEL = Barro and Lee; NSD = Nehru et al.

Our results indicate that the importance of measurement error varies significantly across data sets, although their precise ranking depends on the data transformation that is chosen. Two of the datasets most widely used in early cross-country empirical work, those by Kyriacou (1991) and Barro and Lee (various years), perform relatively well when the data are used in levels but, as Krueger and Lindhal (2001) note, contain very little signal when the data are differenced. Efforts to increase the signal content of the schooling data seem to have been at least partially successful, although the attenuation bias continues to be potentially large even in these cases. Taking as a reference the average reliability ratio for the (1996) version of the Barro and Lee data set (0.206), the 2000 revision of these series by the same authors has increased their information content by $21 \%$, while the estimates reported in Cohen and Soto (2001) and in D\&D (2002) raise the estimated reliability ratio by $162 \%$ and $207 \%$ respectively.

\subsection{Data quality and estimates of the growth effects of human capital in the OECD}

As we have seen in the previous section, the expected severity of the attenuation bias is a decreasing function of the reliability ratio of the series used in the estimation. This suggests that the estimated value of the coefficient of human capital in a growth regression should increase with the quality of the schooling data. In de la Fuente and Doménech (D\&D, 2002 and 2006) we show that this is indeed the case. We estimate various specifications of an aggregate production

estimates of reliability ratios under more general assumptions and find that the required corrections do not qualitatively change the results. 
function using the different schooling series for the OECD countries analyzed in the previous section as alternative proxies for the stock of human capital. We find that both the size and the significance of the coefficient of schooling increase as expected with the reliability ratio. Finally, we exploit this correlation to construct a set of "meta-estimates" of the parameter of interest that correct for measurement error bias. ${ }^{9}$

\section{Results with different schooling series}

The equations we estimate are derived from a Cobb-Douglas aggregate production function with constant returns to scale that includes as inputs the stock of physical capital, the level of employment and the average level of education of the adult population. This equation is estimated in levels (with the variables measured in logarithms), in levels with fixed country effects and in first differences. In D\&D (2002) we also estimate a fourth specification in differences that includes fixed country effects and incorporates a process of technological diffusion or catch-up. In this specification, the rate of growth of TFP is directly proportional to the technological distance between each country and the US, and the fixed country effects capture permanent differences in TFP levels that will presumably reflect differences in R\&D expenditure and other omitted variables. ${ }^{10}$

These specifications are estimated using quinquennial data for our OECD sample that cover the period 1960-90. All equations include fixed period effects (dummy variables for the different sample subperiods). The estimates of the coefficient that measures the elasticity of output with respect to the level of schooling $\left(\alpha_{S}\right)$ obtained with the different specifications and schooling series are shown in Table 2. The last two rows of the table show average coefficient values and $t$ ratios for each data set computed across the different specifications, and the last column reports the average values of $\alpha_{S}$ and the corresponding $t$ statistic computed across data sets for each specification.

The pattern of results that emerges as we change the source of the human capital data is consistent with our hypothesis about the importance of educational data quality for growth estimates. For all the data sets, the estimated value of $\alpha_{s}$ is positive and significant in the specification in levels without fixed country effects (first set of rows in the table), but the size and significance of the estimates increase appreciably as we move to the data sets with higher reliability ratios (which correspond to the last columns of the table). The differences are even sharper when the estimation is repeated with fixed country effects (second set of rows) or with the data in growth rates with or without a catch-up effect (third and fourth blocks). The results

\footnotetext{
${ }^{9}$ A meta-estimate is an estimate that is not obtained directly from the data but is constructed using other primary estimates.

10 All specifications are derived from equation (B.2) in Box 1 using average years of schooling (S) as a proxy for the stock of human capital $(H)$. To indicate this, I use $\alpha_{S}$ (rather than $\alpha_{h}$ ) for the coefficient of schooling in the production function. The last specification (omitted from the published version of the paper for space reasons) also incorporates a technical progress function similar to equation (B.4) in the same Box, except in that the stock of human capital is omitted. Hence, the estimated model does not allow for rate effects. We have tried to incorporate them but the results are not satisfactory. This problem arises frequently in the literature. See de la Fuente and Ciccone (2003) for a discussion of the reasons why it may be difficult to separate the rate and level effects of human capital.
} 
Table 2: Alternative estimates of the human capital coefficient $\left(\alpha_{s}\right)$ using different specifications and schooling series

\begin{tabular}{lccccccccc}
\hline \multirow{4}{*}{ levels } & NSD & $K Y R$ & BEL93 & BEL96 & BEL00 & CES & DED00 & DED02 & avge. \\
& 0.078 & 0.186 & 0.141 & 0.165 & 0.238 & 0.397 & 0.407 & 0.378 & 0.249 \\
fixed eff. & $(2.02)$ & $(2.18)$ & $(4.49)$ & $(4.82)$ & $(6.19)$ & $(7.98)$ & $(7.76)$ & $(6.92)$ & $(5.30)$ \\
& 0.068 & 0.066 & 0.136 & 0.115 & 0.203 & 0.608 & 0.627 & 0.958 & 0.348 \\
differences & $(0.76)$ & $(1.86)$ & $(3.30)$ & $(1.80)$ & $(3.74)$ & $(4.49)$ & $(3.99)$ & $(6.51)$ & $(3.31)$ \\
& 0.079 & 0.009 & 0.089 & 0.083 & 0.079 & 0.525 & 0.520 & 0.744 & 0.266 \\
catch-up & $(0.70)$ & $(0.15)$ & $(2.52)$ & $(1.47)$ & $(1.28)$ & $(2.57)$ & $(2.17)$ & $(3.10)$ & $(1.75)$ \\
& -0.206 & 0.014 & 0.056 & -0.007 & -0.019 & 0.573 & 0.587 & 0.540 & 0.192 \\
& $(1.61)$ & $(0.29)$ & $(1.80)$ & $(0.11)$ & $(0.31)$ & $(3.52)$ & $(3.47)$ & $(2.89)$ & $(1.24)$ \\
average & 0.005 & 0.069 & 0.106 & 0.089 & 0.125 & 0.526 & 0.535 & 0.655 & \\
& $(0.47)$ & $(1.12)$ & $(3.03)$ & $(2.00)$ & $(2.73)$ & $(4.64)$ & $(4.35)$ & $(4.86)$ & \\
& & & & & & & & & \\
\hline
\end{tabular}

- Key: see the notes to Table 3.

obtained with the Kyriacou, B\&L and NSD data in growth rates are consistent with those reported by Kyriacou (1991), Benhabib and Spiegel (1994) and Pritchett (2001), who find insignificant (and sometimes negative) coefficients for human capital in an aggregate production function estimated with differenced data. On the other hand, our series and those of Cohen and Soto produce rather large and precise estimates of the human capital coefficient in most equations and, in the case of our preferred catch-up specification, yield plausible values of the remaining parameters of the model as well, with estimates of $\alpha_{k}$ close to the share of physical capital in national income and positive diffusion coefficients.

\section{Correcting for measurement error bias}

The results summarized in Table 2 strongly suggest that measurement error induces a large downward bias in estimates of human capital coefficients. They also show that improvements in data quality reduce this bias and generate results that are generally more favorable to the view that investment in schooling contributes substantially to productivity growth. To make this point visually, Figure 1 plots the various estimates of $\alpha_{\mathcal{S}}$ given in Table 2 against the corresponding SUR reliability ratios (taken from Table 1), along with the regression lines that summarize the relationship between these two variables for each of the specifications estimated in the previous section. The scatter shows a clear positive correlation between OLS estimates and reliability ratios within each specification and suggests that the true value of $\alpha_{S}$ is at least 0.50 (which is the prediction of the levels equation for $r=1$ ).

As Figure 1 suggests, it is possible to extrapolate the relationship between the reliability ratio and the estimated human capital coefficient that is observed across data sets to estimate the value of $\alpha_{S}$ that would be obtained in the absence of measurement error. In this manner, it is possible to construct meta-estimates of this parameter that will be free of attenuation bias, although this has to be done a bit more carefully than the figure suggests when the growth equation includes additional regressors. 
Figure 1: Estimated $\alpha_{s}$ vs. SUR reliability ratio

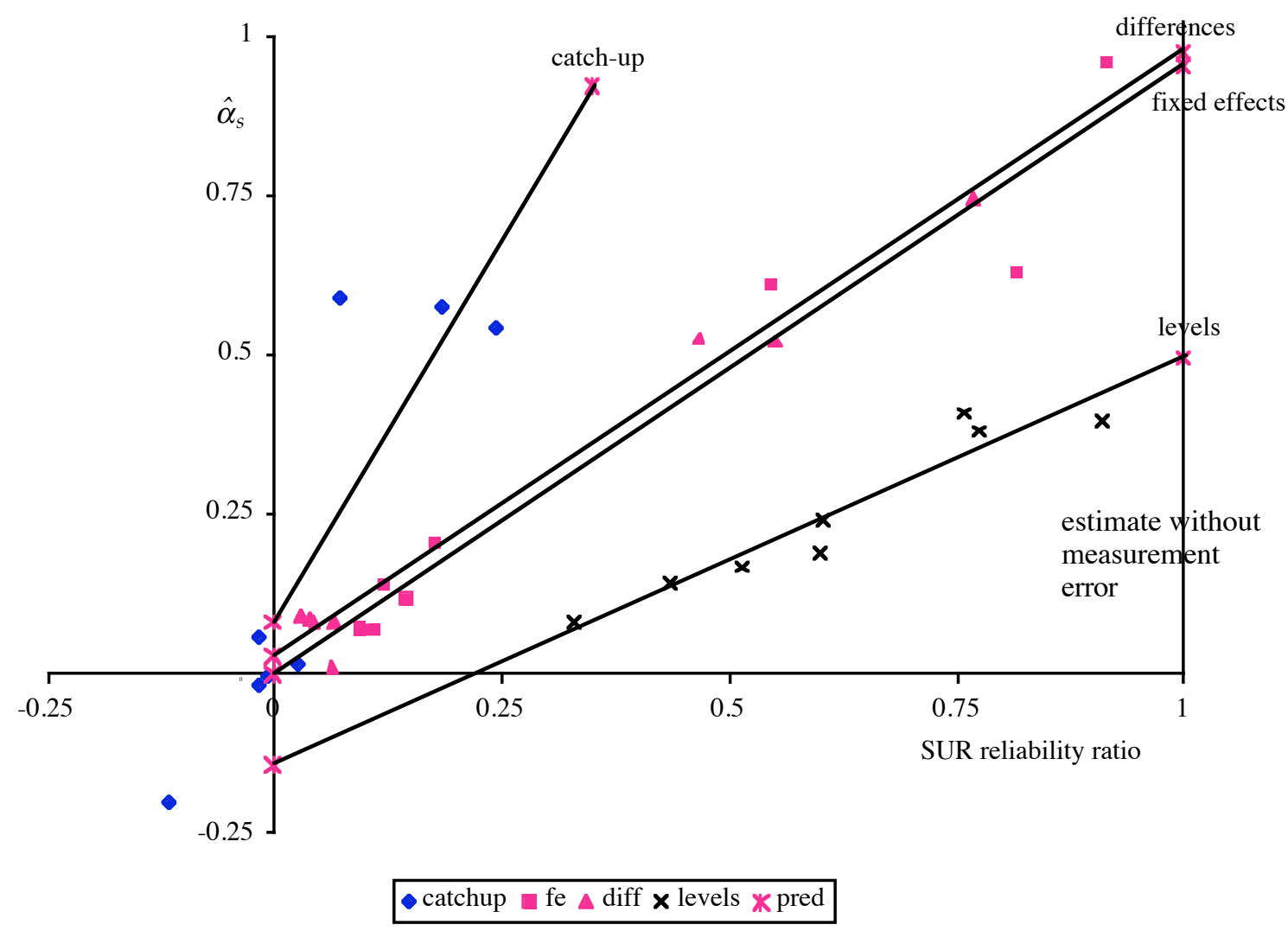

In de la Fuente and Doménech (2002 and 2006) we use a procedure of this type to obtain consistent meta-estimates of $\alpha_{\mathcal{S}}$. Working with the three linear specifications estimated above (that is, with all of them except for the catch-up model) and with different assumptions about the nature of measurement error (and in particular about its correlation across data sets and with the remaining explanatory variables in the model), we obtain different estimates of $\alpha_{S}$ which are then adjusted to account for the possible bias generated by the fact that we are working with the average attainment of the entire population rather than that of employed workers. In this manner, we generate a rather broad range of possible values for $\alpha_{s}$. Under what we consider to be the most plausible assumptions, our results imply values of $\alpha_{S}$ between 0.70 and 0.80 .

It is worth noting that our smallest lower bound for this parameter is 0.57 . This is almost twice as large as Mankiw, Romer and Weil's (1992) estimate of 1/3, which could probably have been considered a consensus value for this parameter in the early 90 s and came then to be seen as too optimistic in the light of the negative results in the literature reviewed in an earlier section. Our estimates, by contrast, point to a considerably higher figure and suggest that investment in human capital is an important growth factor whose effects have been underestimated in previous studies as a result of the poor quality of schooling data. 


\subsection{Regional results for Spain}

Our analysis of Spanish regional data yields qualitatively similar conclusions regarding the contribution of schooling to productivity. In de la Fuente and Doménech (2008), we estimate a catch-up specification using biennial data for the Spanish regions covering the period 1965-95. The specification is identical to the one estimated above for the OECD sample except in that physical capital is now disaggregated into two components, one of which is the stock of productive infrastructures (transport and water supply networks and urban structures). As a proxy for the stock of human capital, we use our own census-based attainment series and an alternative estimate of average years of schooling constructed using Mas et al's (MPUSS, 2002) series on the breakdown of the working-age population by attainment level which is, in turn, based on Labor Force Survey data.

Table 3: Growth estimates with alternative schooling series and specifications

\begin{tabular}{|c|c|c|c|c|}
\hline & [1] & [2] & [3] & [4] \\
\hline$S$ data from: & MPUSS & $D \mathcal{E} D$ & MPUSS & $D \mathcal{E} D$ \\
\hline \multirow[t]{2}{*}{$\alpha_{S}$} & -0.013 & 0.835 & -0.013 & 0.835 \\
\hline & $(0.11)$ & $(2.04)$ & $(0.11)$ & $(4.13)$ \\
\hline $\operatorname{adj} \cdot R^{2}$ & 0.749 & 0.753 & 0.757 & 0.763 \\
\hline regional effects & all & all & signif. & signif. \\
\hline
\end{tabular}

The estimates of the human capital parameter obtained with both schooling series are reported in Table 3. All equations contain period dummies. Equations [1] and [2] contain a full set of regional dummies, and equations [3] and [4] retain only those regional fixed effects that were significant in the first iteration. Inspection of the table reveals two interesting results regarding the coefficient of human capital $\left(\alpha_{S}\right)$. First, this parameter goes from being non-significant when the MPUSS (2002) data are used to having a large and significant value with our attainment series. This result is consistent with our estimates of the information content of the two series, as the relevant reliability ratio is 0.900 for our data and only 0.035 for MPUSS's attainment series when both are measured in logarithmic differences. Second, our estimate of $\alpha_{S}$ for the Spanish regions (0.835) is higher than those reported above for the OECD data using a similar specification ( 0.540 with a full set of country dummies and 0.394 when only the significant fixed effects are retained). Again, the explanation seems to lie at least partly in the information content of the different data sets (the relevant reliability ratio for the cross-country attainment series in D\&D (2006) was 0.246). In fact, our estimate of $\alpha_{\mathcal{S}}$ using Spanish regional data lies well within the range of the meta-estimates obtained by $\mathrm{D} \& \mathrm{D}$ (2006) for OECD countries after correcting for measurement error. 


\subsection{Some implications}

The results summarized in the previous sections have some important implications. If average schooling enters the production function with a coefficient within the range of values we have estimated, differences in school attainment are one of the key sources of productivity differentials across both the OECD countries and the regions of Spain and investment in education yields a rather substantial return that, in most territories, compares quite favorably with that available from alternative investment opportunities.

Figure 2: Contribution of schooling to relative productivity in 1995

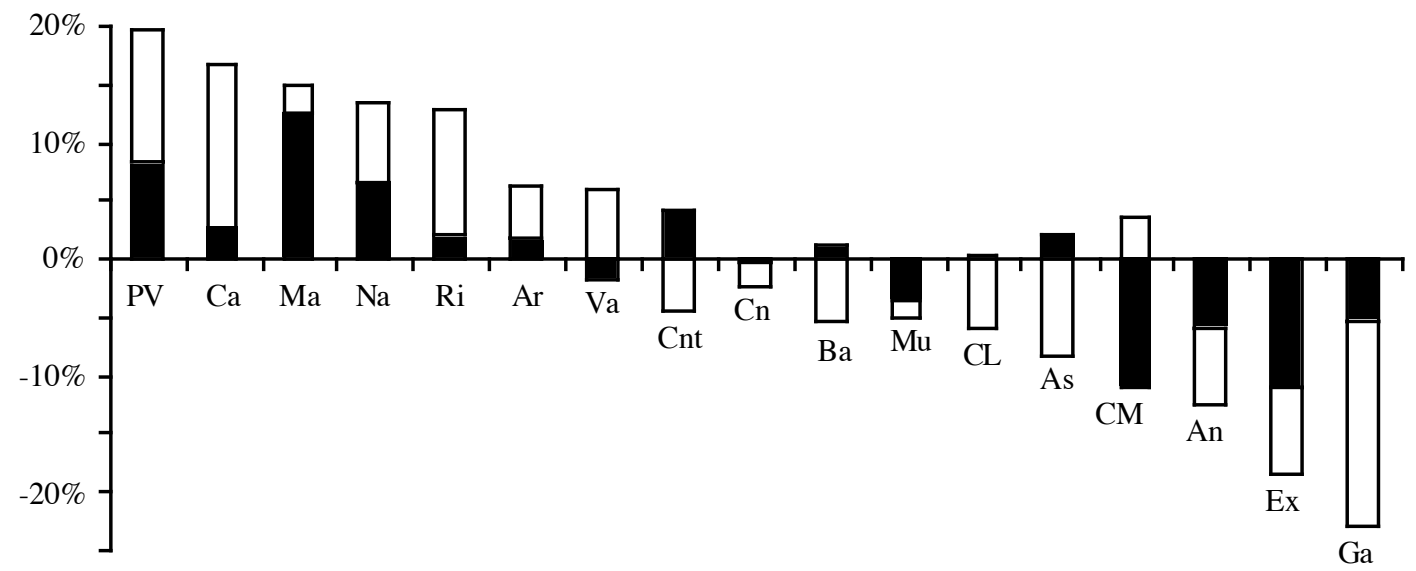

$\mathbf{\text { schooling }}$ Dother factors

- Key: $A n=$ Andalucia; $A r=$ Aragón; $A s=$ Asturias; $B a=$ Baleares; $C n=$ Canarias; $C n t=C a n t a b r i a ; C L=$ Castilla y León; $C M=$ Castilla la Mancha; Cat = Cataluña; $V a=$ Valencia; $E x=$ Extremadura; Ga = Galicia; $M a=$ Madrid; $M u=$ Murcia; $N a=$ Navarra; $P V=$ País Vasco; $R i=$ Rioja.

While I don't have the space that I would need to go into detail, I don't want to close this section without at least a brief elaboration on these two statements. Using the estimates given in Table 3 and the underlying data, in D\&D (2008) we have calculated the contribution of schooling to the relative productivity of the Spanish regions, defined as log real output per job measured in deviations from the (unweighted) sample average of the same variable. Figure 2 shows the decomposition of each region's relative productivity into a schooling-induced component and a residual that captures the joint impact of all other factors. Using regression weights to average the different regions, we find that the share of schooling in relative productivity was $40 \%$ in 1995 -- that is, that for the typical Spanish region schooling accounts for 4/10 of the productivity gap with the sample average. ${ }^{11}$ A similar calculation for the OECD sample implies a share of schooling in relative productivity of $30 \%$.

\footnotetext{
${ }^{11}$ We define the relative productivity of region $i\left(\right.$ qrel $\left._{i}\right)$ as the difference between the region's log output per employed worker and the average value of the same variable in the sample. The contribution of human capital to relative productivity ( $c s_{i}$ ) is obtained multiplying the coefficient of this factor, $\alpha_{s}$, by the relative level of schooling (measured in log differences with the geometric sample mean). After constructing these two variables for each region, we estimate a regression of the form

$\operatorname{cs}_{i}=a *$ rrel $_{i}+e_{i}$
} 
Our estimates also imply that the social returns to education are quite respectable. ${ }^{12}$ Combining our results on the productivity effects of human capital with rough estimates of its impact on employment and with data on educational expenditure, we estimate social rates of return ranging from $10.1 \%$ to $12.6 \%$ in Spain and from $8.3 \%$ to $11.5 \%$ in the EU15. ${ }^{13}$ In both samples, these returns compare quite favorably in most cases with those available from alternative investment opportunities. This suggests that in most of these territories a marginal reallocation of investment resources in favor of education would be socially desirable.

\section{Conclusion}

Academic economists have traditionally been rather optimistic about the contribution of education to economic development and have often assigned to the accumulation of human capital a central role in formal models, particularly in the recent literature on endogenous growth. The results of early empirical studies on the determinants of economic growth have been largely consistent with this view. During the second half of the nineties, however, a new round of empirical papers produced rather disappointing results on the subject that sparked a lively controversy in the literature between "skeptics" and "believers" in the salutary effects of schooling on aggregate productivity growth.

This paper contains a selective and rather partisan review of some of the relevant literature. After setting the stage, it focuses on a problem (the poor quality of cross country schooling data) that may help explain the discouraging results found in some influential studies, on possible ways to overcome it, and on what happens when this is done. I have argued that, due to various deficiencies of the primary data, the schooling series used in the early empirical literature on growth and human capital contain a considerable amount of noise that generates a very substantial downward bias in estimates of the parameter that measures the contribution of educational attainment to productivity. This conclusion is based on the estimation of a statistical indicator of the information content of the schooling series most commonly used in the literature. It is also reinforced by the finding of a clear tendency for human capital coefficients to rise and become more precise as the information content of the schooling data increases. When this relationship is extrapolated to construct estimates of the value of the schooling coefficient that would be obtained in the absence of measurement error, the exercise suggests that the true value of the elasticity of output with respect to the stock of human capital is almost certainly no lower than 0.60 --that is, around twice as high as the most optimistic estimate of reference in the earlier literature on growth and human capital.

where $e_{i}$ is a random disturbance. The coefficient obtained in this manner, $a \cong c s_{i} /$ qrel $_{i}$, measures the fraction of the observed productivity differential that can be attributed to human capital in the sample as a whole.

12 The social rate of return to schooling is defined as the discount rate that equates the present value of the increases in output induced by a marginal increase in average attainment to the present value of the explicit and opportunity costs of schooling. For further details on how this magnitude can be estimated, see de la Fuente (2003).

13 For additional details, see de la Fuente and Doménech (2008) and de la Fuente (2003). 


\section{References}

Azariadis, C. and A. Drazen (1990). "Threshold Externalities in Economic Development." Quarterly Journal of Economics, May, pp. 501-26.

Barro, R. (1991). "Economic Growth in a Cross Section of Countries." Quarterly Journal of Economics CVI (2), pp. 407-43.

Barro, R. (1997). Determinants of economic growth: a cross-country empirical study. Lionel Robbins Lectures, MIT Press, Cambridge, Mass.

Barro, R. and J-W. Lee (1993). "International Comparisons of Educational Attainment." Journal of Monetary Economics 32, pp. 363-94.

Barro, R. and J-W. Lee (1996). "International Measures of Schooling Years and Schooling Quality." American Economic Review 86(2), Papers and Proceedings, pp. 218-23.

Barro, R. and J-W. Lee (2000). "International data on educational attainment, updates and implications." NBER Working Paper no. 7911. (http:/ / www.nber.org/papers/w7911).

Barro, R. and J.-W. Lee (2010). "A new data set of educational attainment in the world, 19502010." NBER Working Paper no. 15902. Cambridge, Mass.

Baumol, W., S. A. Batey Blackman and E. Wolf (1989). Productivity and American Leadership: the Long View. MIT Press.

Behrman, J. and M. Rosenzweig (1994). "Caveat emptor: cross-country data on education and the labor force." Journal of Development Economics 44, pp. 147-71.

Benhabib, J. and M. Spiegel (1994). "The Role of Human Capital in Economic Development: Evidence from Aggregate Cross-Country Data." Journal of Monetary Economics 34, pp. 143-73.

Caselli, F., G. Esquivel and F. Lefort (1996) "Reopening the convergence debate: a new look at cross-country growth empirics." Journal of Economic Growth 1(3), pp. 363-89.

Cohen, D. and M. Soto (2007). "Growth and human capital: good data, good results." Journal of Economic Growth 12(1), pp. 51-76.

Coulombe, S., J. F. Tremblay and S. Marchand (2004). "Literacy scores, human capital and growth across fourteen OECD countries." Statistics Canada.

de la Fuente, A. (2003). "Human capital in a global and knowledge-based economy, part II: assessment at the EU country level." European Commission, DG for Employment and Social Affairs, Brussels. http:/ / digital.csic.es/bitstream/10261/1844/1/57603.pdf

de la Fuente, A. and A. Ciccone (2003). Human capital and growth in a global and knowledge-based economy. European Commission, DG for Employment and Social Affairs. Office for official publications of the European Communities, Luxembourg. http://ideas.repec.org/p/aub/autbar/576.03.html

de la Fuente, A. and R. Doménech (D\&D, 2000). "Human capital in growth regressions: how much difference does data quality make?" OECD Economics Department Working Paper no. 262, Paris.

de la Fuente, A. and R. Doménech (D\&D, 2001a). "Schooling data, technological diffusion and the neoclassical model." American Economic Review 91(2), Papers and Proceedings, pp. 323-27.

de la Fuente, A. and R. Doménech (D\&D, 2001b). "Educational attainment in the OECD, 196090." CEPR Discussion Paper no. 3390. 
de la Fuente, A. and R. Doménech (D\&D, 2002). "Human capital in growth regressions: how much difference does data quality make? An update and further results." CEPR Discussion Paper no. 3587. (http:/ / ideas.repec.org/e/pde52.html\#papers)

de la Fuente, A. and R. Doménech (D\&D, 2006). "Human capital in growth regressions: how much difference does data quality make?" Journal of the European Economic Association 4(1), pp. 1-36.

de la Fuente, A. and R. Doménech (2008). "Human capital, growth and inequality in the Spanish regions." In U. Stierle, M. Stierle, F. Jennings and A. Kuah, editors, Regional Economic Policy in Europe. Challenges for Theory, Empirics and Normative Interventions, pp. 1544. Edward Elgar.

Hanushek, E. and D. Kimko (2000). "Schooling, labor-force quality and the growth of nations." American Economic Review 90(5), pp. 1184-208.

Hanushek, E. and L. Woessmann (2008). "The role of cognitive skills in economic development." Journal of Economic Literature 46(3), pp. 607-68.

Hanushek, E. and L. Wössman (2009). "Do better schools lead to more growth? Cognitive skills, economic outcomes and causation." NBER Working Paper no. 14633, Cambridge, Mass.

Islam, N. (1995). "Growth empirics: a panel data approach." Quarterly Journal of Economics 110, pp. 1127-70.

Krueger, A. and M. Lindahl (2001). "Education for growth: why and for whom?" Journal of Economic Literature XXXIX, pp. 1101-36.

Kyriacou, G. (1991). "Level and Growth Effects of Human Capital, A Cross-Country Study of the Convergence Hypothesis." Mimeo, NYU.

Landau, D. (1983). "Government Expenditure and Economic Growth: a Cross-Country Study." Southern Economic Journal, January, pp. 783-92.

Lau, L, D. Jamison, and F. Louat (1991). "Education and Productivity in Developing Countries: an Aggregate Production Function Approach." Report no. WPS 612, the World Bank.

Lau, L., S. Bhalla and F. Louat (1991). "Human and physical capital stock in developing countries: construction of data and trends." Draft mimeo, World Development Report, World Bank.

Lucas, R. (1988). "On the Mechanics of Economic Development." Journal of Monetary Economics 22 , pp. 3-42.

Mankiw, G., D. Romer and D. Weil (1992). "A Contribution to the Empirics of Economic Growth." Quartely Journal of Economics, pp. 407-37.

Mas. M., F. Pérez, E. Uriel, L. Serrano y A. Soler (2002). "Capital humano, series 1964-2001," en Capital humano y actividad económica (CD Rom). Fundación Bancaja, Valencia.

Nehru, V., E. Swanson and A. Dubey (1995). "A New Database on Human Capital Stocks in Developing and Industrial Countries: Sources, Methodology and Results." Journal of Development Economics, 46, pp. 379-401.

Pritchett, L. (2001). "Where has all the education gone?" World Bank Economic Review 15(3), pp. 367-91. 